\title{
Commentary: Science, Politics, and Risk: Catastrophic Asia from the Perspective of a Brazilianist Anthropologist
}

\section{DONNA M. GOLDSTEIN}

\section{INTRODUCTION}

$\mathrm{T}$ HE FOUR ARTICLES IN this "Catastrophic Asia" collection, while showcasing distinct disciplinary approaches to the subject of what anthropologist George E. Marcus (1994) might identify as "technopolitical" catastrophes, are united in the attempt to uncover the sociopolitical resonances of "manmade" damage in what we take to be regional Asia. In his book Technoscientific Imaginaries, Marcus recognizes that science is deeply political and already embedded in events. In this special section of JAS, anthropologists join with scholars in the physical and natural sciences to apply this idea to catastrophic phenomena, continuing a transdisciplinary conversation that began in April 2014 at the Catastrophic Asia Symposium at the University of Colorado. Here, I contribute to this transdisciplinary enthusiasm by sharing with readers of an Asia-focused journal my own perspectives on catastrophe as a scholar of Brazil and a cultural anthropologist interested in medical anthropology and critical science studies. Specifically, I consider how experts working on issues related to the Angra dos Reis nuclear energy plant in Brazil—the site of my current research-viewed and discussed the Fukushima nuclear plant meltdown of 2011. By reading the current articles through the lens of my own research, I seek to situate catastrophe within a broader anthropological literature on environmental toxicity.

Human impact on the earth's ecosystems has become a central discussion point in the framing of geologic epochs. Although the concept of Anthropocene is not harnessed directly by the authors in this special section, it hovers in the shadows of each of these accounts which, as Tim Oakes notes in his introduction, parallel and extend an earlier discussion that took place in this journal titled "Asian Studies in the Age of the Anthropocene" (JAS 73(4), November 2014). "Anthropocene" is the name given by some physical scientists to what appears to be a new geologic period (Crutzen and Steffen 2003; Crutzen and Stoermer 2000). This interval, thought to characterize the present, has as its defining characteristic the environmental impacts of anthropogenic greenhouse gas emissions, which have been accelerating exponentially since the industrial revolution. The concept has been debated across the social and physical sciences since first proposed at the turn of the millennium: Is there enough evidence to suggest the existence of a new geologic period? If so, what is responsible for it? When did it begin? Indeed, the proposed period is now gaining traction as a rallying point among humanities and social

Donna M. Goldstein (donna.goldstein@colorado.edu) is Professor of Anthropology and Director of the Latin American Studies Center at the University of Colorado Boulder. 
science scholars, with recent work appearing in a variety of disciplinary journals, including the Journal of Asian Studies.

Many of the earliest signatories to this historical label differentiate it from the concept of environmental catastrophe. For instance, when Crutzen and Stoermer $(2000,18)$ write optimistically of the potential of reasoned science to save the Anthropocene from the fate of other geologic periods, they distinguish "major catastrophes" from the longue durée of human-environment interaction:

Without major catastrophes like an enormous volcanic eruption, an unexpected epidemic, a large-scale nuclear war, an asteroid impact, a new ice age, or continued plundering of Earth's resources by partially still primitive technology (the last four dangers can, however, be prevented in a real functioning noösphere) mankind will remain a major geological force for many millennia, maybe millions of years, to come. To develop a world-wide accepted strategy leading to sustainability of ecosystems against human induced stresses will be one of the great future tasks of mankind, requiring intensive research efforts and wise application of the knowledge thus acquired in the noösphere, better known as knowledge or information society. An exciting, but also difficult and daunting task lies ahead of the global research and engineering community to guide mankind towards global, sustainable, environmental management.

For Crutzen and Stoermer, the long-term problems of the Anthropocene can be managed by globally positioned "research efforts and wise application of knowledge," in contrast to the more unexpected effects of a sudden volcanic eruption or epidemic. Yet the authors suggest that some catastrophes-namely, large-scale nuclear war, an asteroid impact, a new ice age, or an industrial accident-might also be "prevented" by scientific intervention. The perceived difference between "human-made" and "naturally occurring" disasters has been challenged by contemporary science and social science scholars, as well as by contributors to this special journal section. The four articles included here demonstrate that catastrophe, whether linked to technology or to nature, is uniquely situated within a present epoch characterized by late capitalist industrialization, neoliberal deregulation, and the difficulties of negotiating global issues that involve environmental risk. This commentary thus places Asia in the Anthropocene by viewing catastrophe as manifested in contemporary intersections of science, politics, and risk (Elverskog 2014; Hudson 2014; Philip 2014).

\section{One Disciplinary Approach}

In just the last decade or so, in my own discipline of anthropology, there have been tectonic shifts in our collective disciplinary thinking about environmental damage and environmental risk. Anthropologists interested in environmental issues have decisively moved away from the conclusions of an early and now classic 1982 book written by anthropologist Mary Douglas and political scientist Aaron Wildavsky, entitled Risk and Culture: An Essay on the Selection of Technological and Environmental Dangers. The text addresses the relationship between culture and perceptions of risk. Specifically, 
the authors analyze elements of the environmental movement-a burgeoning social movement in the timeframe of the book's conception-as portraying irrational aspects of "culture." Writing from a late 1970s anthropological perspective, the authors convey elements of the environmental movement in negative terms (Elliott 1983) and blame the structure of that movement for what they describe as a problematic response to environmental risk. When pointing to the excesses of environmental activists, their work demonstrates a rhetorical move common to the structural anthropology of this timeframe, drawing comparisons between modern beliefs in science and the "superstitious beliefs" of "primitive cultures." While challenging the distinction between science and "superstition" lent analytic strength to a range of other sorts of anthropological issues (as Mary Douglas had done in earlier publications) the decision to relativize-as just another belief system - the science associated with environmental risk has been deeply criticized (Elliott 1983). A proper historicization of this book would recognize its conception and publication as occurring prior to anthropology's full engagement with poststructural approaches. Subsequent work in cultural anthropology became fully influenced by the writings of Michel Foucault, and this turn has generated entirely new projects in the arenas of medicine, the environment, and science studies.

Present-day anthropologists working on environmental concerns have been drawn to the work of Bruno Latour (e.g., Latour 2014; Latour and Woolgar [1979] 1986), Donna Haraway (e.g., Haraway 1992, 1997, 2015), and many other critical science studies scholars. Latour's oeuvre covers a great deal of ground, but for the purposes here, I refer the reader to the message of his 2014 book Politics of Nature: How to Bring the Sciences into Democracy. In this work, Latour seeks to redefine political ecology by emphasizing a point he made in earlier works - that science already involves politics, nature, and knowledge. More importantly, Latour is fully interested in encouraging better collective engagements in spaces where diverse public (geopolitical) deliberations about the state of the planet might take place. Haraway's (1997) ModestWitness@Second_Millenium. Femaleman_Meets_Oncomouse makes a similar point. ModestWitness shows how apparent boundaries between what we might consider nature and culture are fluid rather than fixed. Haraway urges scholars to consider their own "situated knowledges" as an important aspect of scholarship, and one she claims would lead to better problem solving and a more livable future. But her more radical critique of race, class, and gender biases in popular culture representations, together with her engagement with Marxist feminist activism and use of a more confrontational writing style, differentiates her from Latour, as do her more immediate calls for action (e.g., Haraway 2015).

Another central orienting scholar in science studies is Sheila Jasanoff, who recently, together with Sang-Hyun Kim, advanced the concept of "sociotechnical imaginaries" (Jasanoff and Kim 2009, 2015). This concept invites scholars to focus on "how, through the imaginative work of varied social actors, science and technology become enmeshed in performing and producing diverse visions of the collective good, at expanding scales of governance from communities to nation-states to the planet" (Jasanoff and Kim $2015,11)$. Their approach, in alignment with Latour's, suggests that collective thinking and deliberating on these issues is necessary.

Another scholar attempting to tease out the effects of different scales of governance and risk is Ulrich Beck, a German sociologist who has come to speak of "world risk 
society" (Beck 1992, 2006) and who suggests that scholars examine the ways in which society organizes itself to deal with the hazards and insecurities introduced by modernity.

Ideas on science, technology, and risk expressed by these and other scholars provide an intellectual entry point for my response to the articles presented here. So too do elements of my own research on how experts of the nuclear energy industry in one small corner of Brazil understand another Asian catastrophe, Japan's Fukushima.

\section{The Catastrophic Asia Essays}

Each of the four essays in this special section addresses catastrophic events that involve politics, scientific practice, and risk, as well as institutions that impact all three. Each case also offers a distinct reading of the relationship between science and politics, which is at the heart of science studies scholarship. Two of the articles are written by social scientists-specifically, anthropologists-seeking clarity on disasters that have already occurred and are still being considered in medical, scientific, and political domains. In one case, the seemingly placid citizen response and lack of government regulation of possibly radioactive commodities that are being extracted from former Soviet nuclear test sites (Stawkowski), and in the other, victims and citizens seeking an accurate epidemiological understanding of the 1984 deadly chemical gas leak in Bhopal, India (Hanna). Scholars in the fields of atmospheric, oceanic, and environmental science coauthor the third essay, which argues that environmental damage caused by even a limited nuclear attack would create a climate-based loss of agricultural productivity that would lead to "mass starvation globally" and thus cause far more fatalities than the original explosions (Toon et al.). The fourth essay, written by geography, water, and climate change scientists, speaks to climate change and water security issues related to the Hindu Kush Himalayan mountain region. The study predicts that unless geopolitical solutions to distributing water resources are reached, climate change will help usher in conflict and ultimately war to the region (Wilson et al.).

All four essays strongly suggest that individual governments in the form of nationstates are still vital in determining how any particular catastrophe is dealt with. They also point to the potential scale of new institutions that are needed to deal with catastrophic events - institutions meant to go beyond the nation-state. Locating catastrophe in the sociopolitical specifics of Asia, the authors suggest that what we know from the Asian context provides meaningful lessons that can be applied elsewhere. Each essay exposes a unique intersection of science and politics, giving depth to our understanding of institutionalized sociotechnical imaginaries in particular places as well as new dimensions to our own localized understandings of risk. The authors also complicate our understanding of the Anthropocene by locating the cases they analyze in local, regional, and national contexts that are embedded in specific situated histories.

Magdalena Stawkowski's essay addresses post-Cold War and post-Soviet era responses to the report that radioactive coal from Kazakhstan allegedly reached Kyrgyzstan. The context of the Semipalatinsk Nuclear Test site located in Kazakhstan looms over this case because it is where a number of corporations have already been invited to develop extractive industries; radioactive coal was a public reminder of the potential dangers of such a project. Stawkowski describes the test site region as one that is vast 
and unregulated, authoritarian and neoliberal, and located in present-day Kazakhstan where there is enormous enthusiasm for developing extractive industries, in spite of the dangers. There seems to be little worry about the risks of laboring in radioactive hot spots or about the potential for harm or long-term health issues that might emerge in the course of these activities; only the small and mostly non-governmental sector seems to voice any worry at all. Members of communities living on the site, a group Stawkowski knows well in an ethnographic sense, have witnessed the social demise of friends and relatives who have left their homes on the test site and migrated to the cities. The majority have decided to tough it out on the highly toxic rural test site they call home rather than attempt urban migration. Over time, they have even come to believe that they are specifically "adapted" to the radiation exposure that is assumed. Even the local population who stands to lose the most from the environmental repercussions of the proposed mining industry development is not necessarily against it.

The pragmatic interests and risk assessments of local residents happen to coincide with the general position of nuclear scientists working in the nearby city of Kurchatov at the National Nuclear Center of the Republic of Kazakhstan. These nuclear scientists repeatedly broadcast the position that excess radiation exposure at Semipalatinsk is minimal and that low-dose radiation poses no significant threat to human health. Activist groups and journalists, however, assume that corruption runs deep in this region and that scientific expertise is not immune from this corruption. According to Stawkowski, scientists charged with studying the site produce reports that claim that the levels of radioactivity found at the site are safe. In this context, it is also important to remember that globally respected scientific institutions already support the understanding of this site (and others like it) as safe. At the global level, the Japanese studies of the effects of the atomic bomb are still the gold standard for research on radiation effects, and they serve to diminish the possibility of conceptualizing harm from low-dose ionizing radiation (Goldstein and Stawkowski 2015, 20). These post-WWII large-scale studies of low-dose ionizing radiation still hold a great deal of power in the scientific community worldwide, ${ }^{1}$ making it difficult for any contrary conclusions to emerge (Goldstein and Stawkowski 2015). Published studies by scientists in the region are thus quickly interpreted as either potentially corrupt or merely attuning themselves to the classic data. Often, the kinds of studies that would point to safety issues at the site are simply not conceptualized at all, exemplifying what some scholars have termed "undone science" (Frickel et al. 2010; Hess 2007).

Stawkowski's conclusion suggests that these toxic commodities seem to generate "little concern." One could potentially read this as a compelling chapter within a broader genre depicting nihilism in the post-Soviet era. But the dominant scientific understanding of this case is ultimately supported by a broad swath of global scientific institutions that ferociously defend the Western scientific findings of the Japan studies, even in the face of other evidence (Goldstein and Stawkowski 2015). In turn, the local desire to open the nuclear test site in Kazakhstan to mining and other industry coincides with a national desire to do the same. The Kazakh government is keen on solidifying ties to global private enterprise and is not willing to sacrifice its industrial ambitions and opt

${ }^{\mathrm{I}}$ The studies are supported by the prestigious National Academy of Sciences. 
for the protection of an already compromised region. Valerie Kuletz (1998) has documented this process in a parallel location in the American West and understands these sacrificed landscapes as being areas that exhibit environmental racism: that is, entire landscapes marked for sacrifice coincide with politically dispossessed minority populations. Given Kazakhstan's authoritarian politics and export-oriented political economy, together with the failure of migrants who have left the region to succeed in local cultural terms, it makes sense that few are concerned about these "killer commodities."

Bridget Hanna's essay is centered on the scientific community: in this case, the Indian government's Indian Council of Medical Research (ICMR). This institution was ill equipped-both politically and scientifically-to carry out the epidemiological research necessary for producing evidence about the effects of the Bhopal gas leak. This catastrophic event was unprecedented, not just for India but for the entire world. The methods used by the ICMR, while attempting to correlate exposure and neighborhood, apparently had no follow through, leaving the work open to heavy criticism by activist groups who understood the levels of harm differently. Government hospitals, using a simple binary of exposed/unexposed for victim categorization, also could keep only simple records that failed to track patients over time. Hanna's research into these attempts to track catastrophe and catastrophe's health effects alternatively revealed that "the fate of the studies over time has seemed to mirror not scientific imperatives but political ones." Her essay speaks to the failure of scientific epidemiological work to uncover statistical significance in the Bhopal disaster and in turn to how the lack of comprehensive epidemiological studies has left a trail of frustration. Ultimately, the harm from gas exposure appeared to be "chronically unmappable." Hanna concludes that the inability to carry out this research in a manner that could make what happened visible signifies loss not only for the survivors, but also for the advancement of toxic exposure science.

While I understand Hanna's point well, I wonder if epidemiological sciences and other environmental sciences that track the relationship between exposure and health effects are not all wracked by this same problem. Recent work I published with Kira Hall on the politico-scientific configurations that led to a diagnosis of mass hysteria in Le Roy, New York, suggests that "toxic layering" (the possibility of multiple toxic substances in a single site) complicates the establishment of clear causality and creates fatigue among the affected (Goldstein and Hall 2015). This leads me to wonder whether the situation identified by Hanna would have transpired all that differently in a resource-rich country that harbors established communities of epidemiologists: could studies of a chemical gas leak ever produce scientific results that would be relatively well accepted? Let us recall that diverse scientific studies with unique methodologies have challenged the findings of the Japan studies regarding the effects of low-dose ionizing radiation, yet they have been dismissed by dominant scientific communities for lacking adequate statistical power, choosing a control group poorly, or failing to take account of obfuscating life factors (Goldstein 2010, 2013; Goldstein and Stawkowski 2015).

The model described by Owen Toon, Alan Robock, Michael Mills, and Lili Xia provides an example of how difficult it is for an established, ideologically powerful, scientific idea to be replaced or supplanted, even when the context of the original model is no longer in play. The authors seek to dislodge the Cold War-inspired idea known as mutual assured destruction (MAD) and pose instead what they consider to be the more accurate current reality with regard to nuclear weapons arsenals: "Any country 
possessing a nuclear arsenal is on a path leading toward self-assured destruction, and is a threat to people everywhere on Earth." For these scientists, the Cold War dictum that other countries would be afraid of triggering a nuclear conflict and using the nuclear option-a position naturalized in MAD political discourse for many years-has reached an endpoint. That endpoint now exists not because the context of the Cold War is no longer relevant, but because new modeling suggests that even a minor nuclear skirmish could create worldwide environmental damage, including global ozone losses, crop failures, food shortages, and mass starvation. These authors ask us to consider "whether the reasons cited to develop nuclear weapons are valid." They request a more accurate scientific accounting that would outline the devastation, and by so doing, possibly deauthorize the (political) reasons cited by leaders of modern nation-states to develop nuclear weapons.

Questions worth posing to this essay in light of the first two essays discussed earlier are the following: Given the problematic political structures in which scientific work is entrenched in other parts of the world (and at home as well), can scientists-through modeling of the facts as they would have it-ever be successful in deauthorizing particular government-sponsored political discourses? Can scientists remain outside of a particular politics, ethics, or morality? While the first two articles imply that science is only as good as the nation-state it resides in, Toon et al.'s essay intimates that a turn toward better scientific modeling could help refashion political ideology. While I am sympathetic to the critique of MAD offered in this essay, I am less enthusiastic about placing the responsibility for change on scientific models, even when I agree with the political implications of this particular model.

Whether political agendas will respond to scientific modeling is in fact something that we must grapple with as citizens of our current era. In an article originally submitted to a book honoring Donna Haraway (and then rejected), Bruno Latour (2013) creates an imaginary conversation between himself and Haraway that touches on the question of "what to do" in terms of how to work in the political terrain while acknowledging the power of diverse scientific evidence and models:

SHE: - . . Don't you see that everyone is now deconstructing scientific facts? That Bush's advisers are great adepts of "social construction"? That "global warming" has become "climate variations". Can you deny that there is no longer any leverage left if it's forbidden to appeal to true and incontrovertible facts? Who has taught everyone to put scare quotes around "evidence", "truth" and "facts"? Us, my dear, us. Doesn't that worry you to be quoted approvingly by neocons, fundamentalists, reactionaries, obscurantist [sic] of all sorts? In case you don't know, even the radical fascists of the neo-Hindu party in India have become great fans of science studies. Can you deny that, on the whole, we have helped the powerful more than the powerless?

HE: - First, no politician or propagandist ever needed science studies to improve their perverse dealings. Mr. Luntz, the Bush propaganda adviser, for instance, is way ahead of us, whatever we do. As for the fascists, well... And second, yes I agree that we have to be careful, but what I don't get is why we should change course and suddenly, in the middle of our work, turn back to the big politics we have been criticizing for so long to say: "Enough detailed 
studies of how people reach certainty! Let's start loudly denouncing the oppressive powers of domination".

SHE: - But are you not tired of piling case study upon case study? Do we really need to add several decimal points to the many effects of power that we've been unveiling? Is the landscape of the present world not unequal enough for us to see? Don't you realize the extent to which time has changed? Criticizing the solidity of scientific facts is not what is needed any longer. Debunking evidence is not what is called for any more. Everyone does that. On the contrary, we need our evidence back. Proofs. And I am not ashamed to say, truth. How long will you remain blind to the terrifying demonstrations of power and dominations? How long will you remain hidden behind your little finger? (Latour 2013, 3-4)

Latour imagines that his interlocutor regrets the unintended effects of science studies, that is, that critiques of science can enhance uncertainty and produce their own depoliticizing effects. Building on Latour and on this imagined dialogue with Haraway, I am concerned that political bodies are motivated to move only on particular kinds of scientific expertise even when that expertise may be imperfect in any number of ways. When we turn to the complexity of environmental cases, we see that environmental science is easily "outscienced" by forms of scientific expertise that are able to convey a greater degree of certainty (Goldstein and Hall 2015). Uncertainty is in fact a defining characteristic of catastrophic toxic events, whether industrial accidents (Button 2010; Fortun 2001; Hanna 2014), industrial pollution (Auyero and Swistun 2008, 2009; P. Brown 2007; Little 2009, 2014; Reno 2011), or nuclear-era waste exposure (K. Brown 2013; Goldstein 2014; Johnston and Barker 2008; Masco 2006; Petryna 2002; Stawkowski 2014).

The final article, coauthored by physical scientists studying water security in AsiaAlāna Wilson, Sierra Gladfelter, Mark Williams, Sonika Shahi, Prashant Baral, Richard Armstrong, and Adina Racoviteanu—reviews a broad range of scientific literatures as well as the most recent methods for collecting information on snow and glacial melting processes. The authors recognize and highlight their concern that changes in the availability of irrigation waters will impact food security, particularly in the mountainous regions of Asia, and they acknowledge that the inequitable distribution of water resources has the potential to lead to conflict. These authors convey the perspective that solutions to water distribution issues will reside in the political realm and that international cooperation will be necessary in order to avoid conflict. Like Toon et al., they reason that scientists with predictive modeling techniques will therefore play a robust role in the world's future. As it is perhaps beyond the scope of their essay, the authors do not predict how these scientific modeling techniques will be taken up in different national- and global-level contexts for political purposes, but this uptake, of course, is critical for the model's success.

\section{A Fieldnote from BraZiL}

In my own recent research focused on the history, future, and health of populations surrounding nuclear power plants in Angra dos Reis, Brazil, I have become aware of the discourses and technoscientific imaginaries displayed by experts working at or near the 
plant: scientists, evacuation technicians, radiology researchers, engineers, health and environment officials, and medical doctors. During field visits to the Angra dos Reis nuclear plants in Brazil in 2012 and 2015 (see Goldstein 2013, 2015), the nuclear experts that I interviewed were eager to share their thoughts on how the events at Fukushima in 2011 had been incorporated into the Brazilian scenario. In fact, personnel at the plant had at their ready formal PowerPoint presentations designed to address concerns about Fukushima. In other work, I focus on the content of these discussions (e.g., Goldstein, forthcoming), but here I want to share a few important summary findings as they relate to issues discussed in these articles.

I write this fieldnote at a peculiar but compelling moment in Brazilian nuclear politics: government officials from all parties have been embedded in a national corruption scandal and this led to the impeachment of the president, Dilma Rousseff, in August 2016. In addition, one of the most important political figures in the nuclear industry, General Othon Luiz Pinheiro da Silva (vice admiral, naval and mechanical engineer, MIT graduate, and ex-president of Eletronuclear) remains under house arrest after being charged in 2015 with bribery related to the construction of Angra 3. This particular sub-story of the wider national scandal (known as Operation Car Wash) has become known in Brazil as Operation Radioactivity. The discovery of corruption within the nuclear industry produced an outcome that could not have been produced by seemingly anything else: it temporarily suspended the construction of Angra 3.

During the course of my fieldwork, I quickly gathered that there was a political mandate to address the concerns of Fukushima in a formal manner, thus my interviews with experts eventually led to comparisons between Angra and Fukushima. The nuclear workers appeared to be responding not only to the recent memory of Fukushima, but also to widespread knowledge of a credible report authored by a well-respected nuclear engineer trained at MIT named Francisco Corrêa (2012). Corrêa's report was aggressively critical of the Angra 3 project. It was released to Greenpeace and the German media in 2012 under the confrontational title: "Is a Nuclear Catastrophe Potentially Possible in the Angra 3 Plant and What Are Possible Scenarios for This, Based on the Weaknesses of the Planned Design and the Lessons Learnt from Fukushima?" In Corrêa's view, risk assessments sponsored by nuclear scientists and the Brazilian government have downplayed the dangers present at Angra 1 and 2 (all three sites are in one location), among them the existence of regular landslides and flooding. Indeed, Corrêa states that Angra 3 should never have been approved and argues that conflicts of interest present in the Brazilian nuclear industry have produced false ideas about safety.

The report becomes more interesting as a text in hindsight, particularly given that Angra 3 was planned, approved, and implemented in an environment where many people stood to gain a profit from its construction, a point that was pivotal in the case against General Othon. Here is one choice piece excised from Corrêa's report:

Many factors played a role in the Fukushima accident, but what we ultimately viewed here were the consequences of wrong assumptions, a dangerous site, outdated reactor technology, an insufficient safety analysis and a lack of oversight through an independent nuclear safety authority. Each of these risk factors is also present in the Angra 3 project and leads to the conclusion that a catastrophic accident scenario is indeed possible for this plant. (Corrêa 2012, 3) 
The experts at Angra worked hard to distinguish the Brazilian situation from that of Fukushima, anticipating that the public had some temporary awareness of the events in Japan and would want to know how Brazil is different. In addition to self-generated concern emanating from the national-level Brazilian nuclear industry, there was sustained international pressure from Germany-based environmental organizations to address the lessons of Fukushima in Angra. But inside of Brazil, the national debate about nuclear energy remained largely an issue of the past. This point was conveyed to us by activists still living in the region (and no longer organized around this issue), who collectively admitted a certain defeat of their movement. One former, prominent anti-nuclear activist summed up how Angra 3 entered into construction without political debate: "Those who were not favorable [to the construction of Angra 3] were silent," he noted. The long entanglement of the nuclear industry with the military and with an ethos of secrecy, combined with a public relations program that promised new jobs and wealth while underestimating the nearly immediate environmental costs of the construction on the region (e.g., deforestation, lack of sufficient infrastructure to absorb migrant workers) enabled Angra 3 to move forward. No one knew at this time that corruption so thoroughly permeated all levels of the project.

The national institutional story is but one element of the narrative that promotes nuclear energy as safe, environmentally friendly, and without health risk, however. A hard-hitting critique of global institutions managing health risk data about nuclear plants has come from another source. Chris Busby (2015), an epidemiologist working to find an accurate way to calculate cancer risk of populations living near nuclear plants, writes in CounterPunch that the Nuclear Regulatory Commission and the National Academy of Sciences refuse to fund or carry out research on the cancer incidence of populations living near nuclear power plants because they are afraid of what they will find. Busby's critique is pointed at the US milieu, but his point is readily applicable to Brazil. Brazil follows the US guidelines and other internationally based regulatory recommendations, so if these questions are not being asked in the United States, they are definitely not being asked in Brazil. If regulations are weak in the United States and internationally, then it is unlikely that Brazil will add regulatory backbone to questions related to its own plants.

Indeed, discourses related to risk at Angra sound much like they do in the United States, exemplified here in one discussion with a high-level engineer from Eletronuclear who dismissed the risks of Angra with a metaphor common to pro-nuclear technospeak: risk at nuclear plants is similar to "airplane flying":

Angra engineer: Progress always carries a risk, and we studied risk. We study what is acceptable, what is not acceptable. Airplane flying is dangerous, but there is a risk associated with it there, and this risk is acceptable by society. So what we study is: what is the risk acceptable to society? And we will try to minimize this risk. So we work in order to minimize risks. ${ }^{2}$

${ }^{2}$ Eletronuclear nuclear engineer, interview with the author, Angra Nuclear Power Plant, March 2015. 
In his recent work, the German sociologist Ulrich Beck (2013) engages with debates about the long-term effects of global warming, Chernobyl, and Fukushima-events that expose diverse populations across the globe to differing (and unequal) forms and levels of manufactured risk. Beck asserts that class analysis may be too "soft" of a category for what he calls our "second modernity" by calling attention to risk's unequal distribution across the globe. For Beck, second modernity describes the current moment where interlinked processes-including globalization, individualization, the gender revolution, underemployment, and global risks — must be responded to simultaneously. Within second modernity, the institutions created by first modernity, among them the nationstate, no longer function as intended. Beck finds that within this new constellation, risk is also resituated. Thus, a world risk society (Beck 2006, 2007) is one that creates new forms of inequality that exist far beyond the responsive powers of the nation-state. In this brave new world, national boundaries do not carry the same meaning, for risks as diverse as torture, hazardous waste, and controversial scientific research are all exported to low-safety, low-wage, and low-rights countries (Beck 2007, 692-93).

Beck's second modernity formulation has keen meaning in the Brazilian context where I work. While some individual scientists such as Corrêa push back against the dangers of the Angra nuclear plants, Brazil has been meeting since 2008 with representatives from Russia, South Korea, and Japan to explore further possibilities for development of nuclear energy in the country. Perhaps ironically, the same company that was in charge of Fukushima, Tokyo Electric Power Company, has recently bid to export its current technology for small-scale independent nuclear plants to Brazil (NucNet 2013).

Evacuation planning is central to the function of nuclear plants around the globe. In 2015, at the Center for Coordination and Control of Nuclear Emergency, I also spoke to the head of nuclear emergency evacuation planning for the city of Rio de Janeiro, who explained the emergency evacuation plans in place for the Angra nuclear complex. ${ }^{3}$ The plan calls for evacuation of populations from 3 to 5 kilometers from the plant as configured by concentric circles radiating away from the plants. This would send thousands of evacuees to the city of Angra, an urban enclave that lies just 15 kilometers from the complex. The nature of the evacuation would of course depend on the kind of accident, but the evacuation issue is gaining credibility among different national and global interests in spite of criticism. Current US National Regulatory Commission regulations call for a 10-mile evacuation zone around nuclear plants, but other experts, such as the Physicians for Social Responsibility (PSR), call for a 50-mile evacuation zone. PSR notes that the numbers of people that would need to be evacuated from a 50-mile radius would make clear to the undecided how unrealistic these evacuation plans are (Physicians for Social Responsibility 2011). As a globally situated anti-nuclear activist organization, PSR speaks against current regulatory complaisance and it provides some perspective on what some might call a weak global regulatory environment.

Returning to Beck's point about second modernity: global scientific institutions, such as those that set target evacuation zones, are also eligible for critique. Recall the moment in the Fukushima crisis when both the US and Japanese governments suggested evacuation of populations within a 12-mile radius. Just a few days later, President Obama

${ }^{3}$ CCCEEN official, interview with the author, Angra dos Reis, March 2015. 
suggested evacuation to a 50-mile radius (Keyes 2011). Beck suggests that even while science is developing new and denser forms of knowledge, it is simultaneously producing a greater lack of certainty and clarity. In other words, it is becoming more difficult to produce knowledge that leads to solid, unambiguous decisions (Beck and Lau 2005, 528).

This point strongly aligns with the themes explored by the first two articles in this special section of JAS. Both cases highlight uncertainty in the realm of toxicity, catastrophe, and health risk and suggest that in some instances neither national nor global institutions can relieve the problem. The Brazilian case is similar. Few Brazilians are even aware that nuclear power already exists in Brazil. Because the country's history of nuclear energy began with military control over the plants and the information distributed about them, very few voices have been able to counter traditional pro-nuclear perspectives with the appropriate authority and knowledge to speak about alternative perspectives. The majority of experts on nuclear energy in Brazil are already working deep within the industry. As in other contexts around the globe, both left-wing and right-wing parties and governments in Brazil have thus far been nearly unanimous in their support of nuclear energy development. Experts and the science produced in the context of scientific institutions in Brazil are thus already fully integrated into the flows and troubles of this second modernity. Beck argues that much of earlier critical social theory becomes antiquated within second modernity, and this example helps illustrate his point. In Beck's thesis, we are all still attempting to deal with global-level risk through the institutions of first modernity, or rather, the modernity that necessarily privileges nation-states. His direction of thinking forces us to reposition questions related to the Anthropocene and technopolitics within a framework that extends beyond local, regional, or national settings and into global settings.

Yet without attention to the close-up, local textures surrounding catastrophic events, as we saw in the articles by Stawkowski and Hanna, we would lose the situated knowledge that examines what has taken place and how it is understood. Beck also understands that a "cosmopolitan sociology" is needed to face the combined challenges of global- and national-level risk, a point implied by the second two articles in their reference to globallevel institutions tasked with providing new legitimacy to the questions that are being asked. Yet as we see in the case of these articles and in the case of Brazil, global-level institutions and the regulations associated with those institutions do not automatically resolve questions of uncertainty or ambiguity. The move to a global scale of reference cannot fully guarantee the quality of the scientific research as much as some might hope.

\section{Concluding Remarks}

The essays in this special section converge around the idea that scientific knowledge, politics, and nature are already deeply intertwined and cannot easily be divided into neat and distinct categories. They differ, however, on the subtle point made by Latour in his imagined conversation with Haraway regarding the place of scientific knowledge and scientific institutions in our comprehension of environmental catastrophe. Over two decades ago, Sandra Harding (1992) argued in "After the Neutrality Ideal" that the expectation of a neutrally objective science is perhaps no longer viable. Harding points to historical evidence that suggests that what could have once been considered scientific 
neutrality — and for some still remains an ideal — cannot be defended in light of the distortions and exploitive consequences that shape science when it enters the social realm. Latour would probably agree with this assessment, as his work examines the evolving relationship between science and social life to illustrate the intensely social and political nature of scientific experimentation (Latour 1993; Latour and Woolgar [1979] 1986). Haraway would also agree with Harding's point, although (according to Latour) she might focus on the unequal power differences existing in different social and institutional settings that block particular points of view from being heard.

The India and Kazakhstan cases point to the political nature of scientific work. Without rejecting or invoking an anti-scientific stance, the essays by Hanna and Stawkowski advocate a kind of skepticism regarding what we claim to know. But they also leave room to imagine something different, should political contexts have better resources or involve less corruption.

The second pair of essays, written by physical scientists in collaboration, argue for a new sort of scientific rationality and utility that would minimally provide scientists with a seat at the political table and maximally provide the expertise leading to well-reasoned political solutions to catastrophes in the making. Toon et al.'s essay certainly suggests a needed paradigm shift away from Cold War projections about nuclear war and MAD; their claim rests on what they consider better scientific modeling and forecasting of what an actual nuclear war would unleash. Wilson et al.'s article suggests that new scientific methodologies that provide far more accurate accounts of long-term shifts in water availability should inform the global bodies that regulate the transnational water ecumene. The implication is that national-level institutions may not have the full capacity to carry out these new methods.

My concern with the anthropologically oriented essays is the following: how can we, as social scientists and anthropologists, analyze the production of knowledge in "local" scientific cultures in light of global standards of (purported) excellence? My concern with the physical science-oriented essays is different: do the proposed scientific research projects - taking place in scientific institutions located in the West—still privilege Big Data (and the associated methods of mathematical modeling that privilege large-scale data sets) and unwittingly deauthorize other forms of knowledge? How do we know if we are asking good questions? Do these sorts of models have the potential, as Geoffrey Bowker (2014) suggests, to reduce what it means to "know"? Where does local knowledge stand in these instances? It would seem unwise to authorize science alone as providing us with the truth, since there is evidence that there are indeed hidden politics, ethics, and morality in all assessments of risk, no matter what the scientific quality of the data. Let us be reminded that life in the world risk society entails that "science, the state and the military are becoming part of the problem they are supposed to solve" (Beck 2006, 338). The Brazil case stands as a potent example of this entailment, given the limited number of qualified voices able to speak to issues associated with the country's growing nuclear power industry; the embedded corruption within the government and the energy sector; and the ambiguity of the science of radiation, evacuation during a crisis, and long- and short-term health risks associated with nuclear energy.

The four articles included in this special section all address problems of living in a world risk society situated in the age of the Anthropocene. The two written by anthropologists portray environmental damages and human suffering as deeply bound to manmade 
technological "advances" of the twentieth century: nuclear testing and its consequences in the case of Semipalatinsk, and the production of toxic agrochemicals in the case of Bhopal. Both of these articles provide some evidence for how these technologies became part of the problem they were supposed to solve, and of how world risk was redistributed to the doorsteps of the impoverished. The two written by scientists in collaboration, when positioned together with these more ethnographic accounts of the technopolitics surrounding catastrophe, remind us of the political work that must be done to allow new scientific models to enter the field of play. My hesitation to privilege scientific modeling is not that I am skeptical of the findings displayed in these essays (which I find powerful) or of the desire of these scientists to entire the political realm (which I find refreshing). Rather, in the spirit of both Haraway and Latour, I want to stress the importance of acknowledging the situatedness of produced knowledge, as well as the contextual constraints that limit what we choose to do with it.

\section{Acknowledgments}

Many kind thanks to Tim Oakes and Carla Jones for hosting the Catastrophic Asia Symposium and to Tim for his steady editorial skills. Additional thanks to the participants and authors represented here, in particular Magda Stawkowski for the many fruitful and productive exchanges of ideas. Thanks to copyeditor Andrea Kingston for her fine editorial skills. Final thanks to Kira Hall for being the best interlocutor.

\section{List of References}

Auyero, Javier, and Debora Alejandra Swistun. 2008. "The Social Production of Toxic Uncertainty." American Sociological Review 73(3):357-79.

—. 2009. Flammable: Environmental Suffering in an Argentine Shantytown. Oxford: Oxford University Press.

Beck, UlRich. 1992. Risk Society: Towards a New Modernity. London: Sage Publications.

2006. "Living in the World Risk Society." Economy and Society 35(3):329-45.

—. 2007. "Beyond Class and Nation: Reframing Social Inequalities in a Globalizing World." British Journal of Sociology 58(4):679-705.

— . 2013. "Why 'Class' Is Too Soft a Category to Capture the Explosiveness of Social Inequality at the Beginning of the Twenty-First Century." British Journal of Sociology 64(1):63-74.

Beck, Ulrich, and C. Lau. 2005. "Second Modernity as a Research Agenda: Theoretical and Empirical Explorations in the 'Meta-change' of Modern Society." British Journal of Sociology 56(4):525-57.

Bowker, Geoffrey. 2014. “The Theory/Data Thing.” International Journal of Communication 8:1795-99.

Brown, Kate. 2013. Plutopia: Nuclear Families, Atomic Cities, and the Great Soviet and American Plutonium Disasters. New York: Oxford University Press.

Brown, Phil. 2007. Toxic Exposures: Contested Illnesses and the Environmental Health Movement. New York: Columbia University Press. 
Busby, Chris. 2015. "Nuclear Power Kills: The Real Reason the NRC Canceled Its Nuclear Site Cancer Study.” CounterPunch, September 22. http://www.counterpunch.org/2015/09/22/nuclear-power-kills-the-real-reason-the-nrc-canceled-its-nuclearsite-cancer-study/ (accessed October 20, 2015).

Button, Gregory. 2010. Disaster Culture: Knowledge and Uncertainty in the Wake of Human and Environmental Catastrophe. Walnut Creek, Calif.: Left Coast Press.

Corrêa, Francisco. 2012. "Is a Nuclear Catastrophe Potentially Possible in the Angra 3 Plant and What Are Possible Scenarios for This, Based on the Weaknesses of the Planned Design and the Lessons Learnt from Fukushima?" Greenpeace, February 28. http://www.greenpeace.org/brasil/Global/brasil/report/2012/Angra3\%20security. pdf (accessed March 10, 2015).

Crutzen, Paul J., and Will Steffen. 2003. "How Long Have We Been in the Anthropocene Era?" Climate Change 61(3):251-57.

Crutzen, Paul J., and Eugene F. Stoermer. 2000. "The 'Anthropocene.”' Global Change Newsletter 41:17-18.

Douglas, Mary, and Aaron B. Wildavsky. 1982. Risk and Culture: An Essay on the Selection of Technological and Environmental Dangers. Berkeley: University of California Press.

Elliott, E. Donald. 1983. "Risk and Culture: An Essay on the Selection of Technical and Environmental Dangers” (book review). Faculty Scholarship Series 2192. http://digitalcommons.law.yale.edu/fss_papers/2192 (accessed February 25, 2017).

Elverskog, Johan. 2014. “(Asian Studies + Anthropocene) $)^{4}$." Journal of Asian Studies 73 (4):963-74.

Fortun, Kim. 2001. Advocacy after Bhopal: Environmentalism, Disaster, New Global Orders. Chicago: University of Chicago Press.

Frickel, Scott, Sahra Gibbon, Jeff Howard, Joanna Kempner, Gwen Ottinger, and David Hess. 2010. "Undone Science: Charting Social Movement and Civil Society Challenges to Research Agenda Setting." Science, Technology, and Human Values 35(4):444-73.

Goldstein, Donna M. 2010. "Experimentalité: Pharmaceutical Insights into Anthropology's Epistemologically Fractured Self." In Medicine and the Politics of Knowledge, ed. Susan Levine, 119-52. Cape Town: HSRC Press.

2013. "Preface to the 2013 Edition." In Laughter Out of Place: Race, Class, Violence, and Sexuality in a Rio Shantytown, xix-xxxv. Berkeley: University of California Press.

2014. "Toxic Uncertainties of a Nuclear Era: Anthropology, History, Memoir." American Ethnologist 41(3):579-84.

. 2015. "The Nuclear Option: For Anthropologists Who Have Considered Humor When the Drive to Modernity Is Not Enough." Savage Minds, April 6. http://savageminds.org/2015/04/06/the-nuclear-option-for-anthropologists-who-have-consideredhumor-when-the-drive-to-modernity-is-not-enough/ (accessed February 25, 2017).

. Forthcoming. "Undone Science in the Brazilian Nuclear Contact Zone: How Angra Nuclear Workers Processed Fukushima." Culture, Theory and Critique.

Goldstein, Donna M., and Kira Hall. 2015. "Mass Hysteria in Le Roy, New York: How Brain Experts Materialized Truth and Outscienced Environmental Inquiry." American Ethnologist 42(4):640-57.

Goldstein, Donna M., and Magdalena E. Stawkowski. 2015. "James V. Neel and Yuri E. Dubrova: Cold War Debates and the Genetic Effects of Low-Dose Radiation." Journal of the History of Biology 48(1):67-98. 
Hanna, Bridget. 2014. "Toxic Relief: Science, Uncertainty, and Medicine after Bhopal." PhD diss., Harvard University.

Haraway, Donna. 1992. "The Promises of Monsters: A Regenerative Politics for Inappropriate/d Others." In Cultural Studies, eds. Lawrence Grossberg, Cary Nelson, and Paula Treichler, 295-337. New York: Routledge.

_.1997. ModestWitness@Second_Millenium.Femaleman_Meets_Oncomouse:Feminism and Technoscience. New York: Routledge.

_ . 2015. "Anthropocene, Capitalocene, Plantationocene, Chthulucene: Making Kin.” Environmental Humanities 6(1):159-65.

Harding, Sandra. 1992. "After the Neutrality Ideal: Science, Politics, and 'Strong Objectivity." Social Research 59(3):567-87.

Hess, David. 2007. Alternative Pathways in Science and Industry: Activism, Innovation, and the Environment in an Era of Globalization. Cambridge, Mass.: MIT Press.

Hudson, Mark. 2014. "Placing Asia in the Anthropocene: Histories, Vulnerabilities, Responses." Journal of Asian Studies 73(4):941-62.

Jasanoff, Sheila, and Sang-Hyun Kim. 2009. "Containing the Atom: Sociotechnical Imaginaries and Nuclear Power in the United States and South Korea." Minerva 47:119-46.

— cation of Power. Chicago: University of Chicago Press.

Johnston, Barbara Rose, and Holly M. Barker. 2008. The Consequential Damages of Nuclear War: The Rongelap Report. Walnut Creek, Calif.: Left Coast Press.

Keyes, Charley. 2011. "U.S. Breaks from Japan, Expands Evacuation Zone Near Stricken Reactors." CNN, March 16. http://www.cnn.com/2011/POLITICS/03/16/us.japan. evacuation/ (accessed April 18, 2016).

KuletZ, VAlerie. 1998. The Tainted Desert: Environmental Ruin in the American West. New York: Routledge.

Latour, Bruno. 1993. We Have Never Been Modern. Cambridge, Mass.: Harvard University Press.

— 2013. "Critical Distance or Critical Proximity? Dialogue Prepared for a Volume in Honor of Donna Haraway.” Edited by Sharon Ghamari. http://www.bruno-latour.fr/ sites/default/files/P-113-HARAWAY.pdf (accessed October 3, 2015).

- 2014. Politics of Nature: How to Bring the Sciences into Democracy. Cambridge, Mass.: Harvard University Press.

Latour, Bruno, and Steven Woolgar. [1979] 1986. Laboratory Life: The Construction of Scientific Facts. Princeton, N.J.: Princeton University Press.

Little, Peter C. 2009. "Negotiating Community Engagement and Science in the Federal Environmental Public Health Sector.” Medical Anthropology 23(2):94-118.

_ 2014. Toxic Town: IBM, Pollution, and Industrial Risks. New York: New York University Press.

Marcus, George, ed. 1994. Technoscientific Imaginaries: Conversations, Profiles, and Memoirs. Chicago: University of Chicago Press.

Masco, Joseph. 2006. The Nuclear Borderlands: The Manhattan Project in Post-Cold War New Mexico. Princeton, N.J.: Princeton University Press.

NucNet. 2013. http://www.nucnet.org/all-the-news/2013/06/11/russia-ready-to-invest-inbrazil-s-nuclear-energy-programme (accessed October 21, 2014).

Petryna, Adriana. 2002. Life Exposed: Biological Citizens after Chernobyl. Princeton,

N.J.: Princeton University Press. 
Philip, Kavita. 2014. "Doing Interdisciplinary Asian Studies in the Age of the Anthropocene." Journal of Asian Studies 73(4):975-87.

Physicians for Social Responsibility. 2011. "Evacuation Zones for Nuclear Reactors." http://www.psr.org/resources/evacuation-zone-nuclear-reactors.html?referrer=http://www.psr.org/search.jsp?query=20nuclear20plant\%20evacuation (accessed April 16, 2016).

Reno, Joshua. 2011. "Beyond Risk: Emplacement and the Production of Environmental Evidence.” American Ethnologist 38(3):516-30.

Stawkowski, Magdalena E. 2014. “Radioactive Knowledge’: State Control of Scientific Information in Post-Soviet Kazakhstan.” PhD diss., University of Colorado Boulder. 